\title{
Análise comparativa da tensão limite de escoamento de argamassas por meio da técnica de Pashias e reometria rotacional
}

\author{
Comparative analysis of yield stress of \\ mortars by Pashias technique and \\ rotational rheometry
}

Geraldo de Freitas Maciel ${ }^{1}$, Mônica Pinto Barbosa ${ }^{2}$, Joao Batista Pereira ${ }^{3}$

\footnotetext{
${ }^{1}$ Professor Titular do Departamento de Engenharia Civil, Universidade Estadual Paulista (UNESP), Campus de Ilha Solteira, Caixa Postal 31; CEP 15385-000, Ilha Solteira - SP

e-mail: geraldo.maciel3@gmail.com

${ }^{2}$ Professora Doutora- Livre-Docente e Pesquisadora da Faculdade de Engenharia Civil, Pontifícia Universidade Católica de Campinas (PUC-Campinas), Caixa Postal 317; CEP 13086-900, Campinas - SP

e-mail: monica_eng_civil@yahoo.com.br

${ }^{3}$ Engenheiro Civil, Mestrando, Universidade Estadual Paulista (UNESP), Campus de Illha Solteira Caixa Postal 31; CEP 15385-000, Illha Solteira - SP

e-mail: joao-batista75@hotmail.com
}

\section{RESUMO}

Estudos referentes ao comportamento reológico de materiais cimentícios, sobretudo de argamassas e concretos, vêm sendo desenvolvidos a fim de melhorar a qualidade e a durabilidade destes materiais, bem como prevenir eventuais problemas, quando no estado endurecido. A reometria rotacional é o ensaio clássico para a caracterização reológica dos materiais cimentícios no estado fresco, pois permite inferir a tensão limite de escoamento e a viscosidade aparente do material. Os reômetros rotacionais, entretanto, são equipamentos de elevado custo, o que tem levado ao desenvolvimento de métodos de baixo custo, como a técnica de Pashias. A técnica de Pashias é uma modificação do procedimento de slump-test, a fim de caracterizar, reologicamente, os materiais através da determinação única da tensão limite de escoamento. O trabalho desenvolvido teve como objetivo determinar a tensão limite de escoamento de argamassas provenientes de composições de concretos de alto desempenho (CAD), dosados por meio de conceitos de reologia e empacotamento de partículas. Para tanto, utilizou-se o ensaio reométrico clássico e a técnica de Pashias (cilindro), a fim de comparar os resultados e avaliar a capacidade da técnica alternativa na determinação da tensão limite de escoamento de argamassas. A comparação dos resultados obtidos pelos diferentes métodos de ensaio reológico utilizados demonstrou uma boa capacidade da técnica de Pashias (técnica alternativa) em avaliar o parâmetro tensão limite de escoamento de argamassas (com erros variando de 1 a 20\%). Ademais, observou-se que a argamassa obtida a partir do CAD dosado pelo conceito de empacotamento de partículas apresentou-se mais fluida e trabalhável, com menor tensão limite de escoamento.

Palavras-chave: Argamassa, técnica de Pashias, reometria, tensão limite de escoamento, empacotamento de partículas.

\begin{abstract}
Studies about the rheological behavior of cementitious materials, especially mortars and concretes, have been developed to improve the quality and durability of these materials as well as prevent any future problems in the hardened state. The rotational rheometry is the classic test for the rheological characterization of cementitious materials, because it allows to infer about the level of yield stress and apparent viscosity of the material. The rotational rheometers are, however, costly equipments, which led to the development of alternative methods for low cost, as the Pashias technique. The Pashias technique is a modification of the slump-test procedure in order to characterize, rheologically, the materials by single determining of the yield stress. The work developed aimed to determine the yield stress of mortars from compositions of high performance concretes (HPC) dosed by the concepts of rheology and particles packing. For this, it was used the classic rheometric
\end{abstract}


test and the Pashias technique (cylinder), in order to compare the results, and evaluate the capacity of alternative technique in determining the yield stress of mortars. The comparison of the results obtained by different rheological test methods showed a good ability of the Pashias technique (alternative technique) to evaluate the of yield stress parameter of mortars (with errors ranging from $1 \%$ to $20 \%$ ). In addition, was observed that the mortar obtained from HPC dosed by the concepts of particles packing appeared more fluid and workable, with less yield stress.

Keywords: Mortar, Pashias technique, rheometry, yield stress, particle packing.

\section{INTRODUÇÃO}

O concreto, composto por agregado graúdo, agregado miúdo, cimento, água e, em casos especiais, aditivos químicos e adições minerais, é o material mais utilizado na indústria da construção civil. Em virtude disso, muitas pesquisas vêm sendo desenvolvidas com o propósito de melhorar as propriedades mecânicas e reológicas deste material. O controle de qualidade do concreto, na maioria das vezes, é realizado no estado endurecido, porém para garantir a qualidade do compósito, é necessário também estudar o seu comportamento reológico quando no estado fresco, e para isso utiliza-se, comumente, o slump test.

Diversos materiais utilizados na indústria (seja de construção civil, de mineração, de petróleo, de alimentos, etc) apresentam o comportamento típico de um fluido que começa a escoar quando aplicada uma mínima tensão: a tensão limite de escoamento [1,2]. Essa propriedade do material pode ser medida por diferentes técnicas [2], destacando-se o slump test como uma técnica robusta, barata e rápida [3, 4].

O modelo de previsão da tensão limite de escoamento, a partir da medida de slump do material, foi inicialmente idealizado por MURATA [5], a partir do molde de geometria cônica e análise de materiais cimentícos (concretos e argamassas), sendo, na sequência, corrigido e consolidado por CHRISTENSEN [6], também considerando geometria cônica. PASHIAS [4] adapta a teoria de previsão de tensão limite de escoamento a partir do cone de Abrams para a geometria cilíndrica, obtendo bons resultados para suspensões altamente floculadas, mostrando-se eficiente e de baixo custo.

Diversos outros estudos vêm demonstrando a eficácia da técnica de Pashias na previsão de tensões limite de escoamento, como o trabalho de BAUDEZ et al. [7] que testa a técnica tanto para soluções de base mineralógica, quanto para materiais de base polimérica (géis de carbopol). Na mesma direção, os trabalhos mais recentes de PIERRE et al. [8] trazem soluções analíticas para o cálculo da tensão limite de escoamento em situação de dinâmica dominada, seja pela ação do peso do material (fase puramente inercial), seja pela ação do efeito viscoso (fase viscosa), seja pela ação da elevada fluidez, fases estas intimamente associadas e determinantes para o campo de velocidade do espraiamento do material que, em definitivo, vai explicar o abatimento final.

Sabe-se também que a distribuição granulométrica e o empacotamento das partículas têm forte influência no comportamento reológico do material, através da relação direta entre sua fluidez e granulometria [9]. O estudo de empacotamento de partículas está relacionado à correta seleção da proporção e do tamanho adequado dos materiais particulados, de forma que os vazios maiores sejam preenchidos com partículas menores, cujos vazios serão novamente preenchidos com partículas ainda menores e assim sucessivamente [10].

Segundo CASTRO e PANDOLFELLI [11], os estudos teóricos e experimentais relacionados ao empacotamento de partículas, quando da aplicação desses conceitos na busca de melhores composições de argamassas, têm convergido para a propositura do modelo de Alfred, proposto por DINGER e FUNK [12].

Nessa perspectiva, o trabalho tem por objeto determinar e comparar a tensão limite de escoamento de argamassas, provenientes de composições de concretos de alto desempenho (CAD), por meio do ensaio de reometria clássica e técnica alternativa de Pashias. As argamassas utilizadas neste trabalho provêm de concreto de alto desempenho dosado por OLIVEIRA [10].

\subsection{Reologia dos materiais cimentícios}

Os materiais de base cimentícia, com destaque para os concretos e argamassas, são compósitos constituídos pela concentração de partículas sólidas (agregados) em uma suspensão viscosa (pasta de cimento). Esta pasta de cimento, por sua vez, caracteriza-se como uma suspensão, sendo constituída por partículas (grãos de cimento) e um líquido (água). Assim, o concreto e a argamassa no estado fresco, em uma escala macroscópica, fluem como um líquido [13], o que torna adequado o uso da reologia para estudar o comportamento desses materiais.

De uma maneira geral, as diversas campanhas realizadas com materiais de base cimentícia têm mos- 
trado, conforme a literatura $[14,15,16]$, uma boa adequação do comportamento desses materiais aos modelos reológicos (em regime permanente) de Herschel-Bulkely e Bingham.

Nos últimos anos, a reologia dos materiais cimentícios tem sido estudada por meio de ensaios simples e práticos, como o próprio ensaio de slump test $[17,18]$ e o teste da calha $[19,20,21]$, e por ensaios mais sofisticados, como os ensaios reométricos [11]. Os ensaios reométricos possibilitam estudar as curvas de fluxo assim como o comportamento da tensão limite de escoamento e da viscosidade, entretanto, os reômetros são de elevado custo, o que levou ao desenvolvimento de métodos alternativos de baixo custo, como a técnica do plano inclinado (calha), a técnica de Pashias, entre outros.

\subsubsection{Reometria rotacional}

A reometria rotacional, como a dos cilindros coaxiais, placa-cone e placa-placa, são geometrias, largamente presentes nos reômetros, que nos permitem avaliar as propriedades reológicas de fluidos e suspensões, e que podem ser utilizados para estudos práticos e medidas de controle de qualidade do material. Os reômetros fornecem parâmetros fundamentais para a descrição do comportamento reológico, tais como a tensão limite de escoamento, índices de consistência, de escoamento, além da viscosidade [22].

Os reômetros fornecem um maior número de informações quando comparados aos ensaios empíricos. Além disso, as informações obtidas são mais objetivas, já que o ensaio é totalmente automatizado, dispondo de softwares que permitem ajustar modelos reológicos clássicos [9]. Existem diversos tipos de reômetros, sendo um dos mais comuns o reômetro de geometria Couette (cilindro coaxiais), constituído por um cilindro interno (spindle) e outro externo (copo) [23].

Pode-se também utilizar o sistema Vane (ou geometria Vane), dispositivo vantajoso para ensaios em sistemas particulados com partículas maiores que as especificadas para ensaios no reômetro tipo cilindros coaxiais [24]. A palheta do Vane (com diâmetro DP) é caracterizada por possuir uma superfície plana de medição que essencialmente se fixa ao material amostrado e efetivamente o empurra quando o movimento de rotação ocorre, conforme ilustrado na Figura 1.

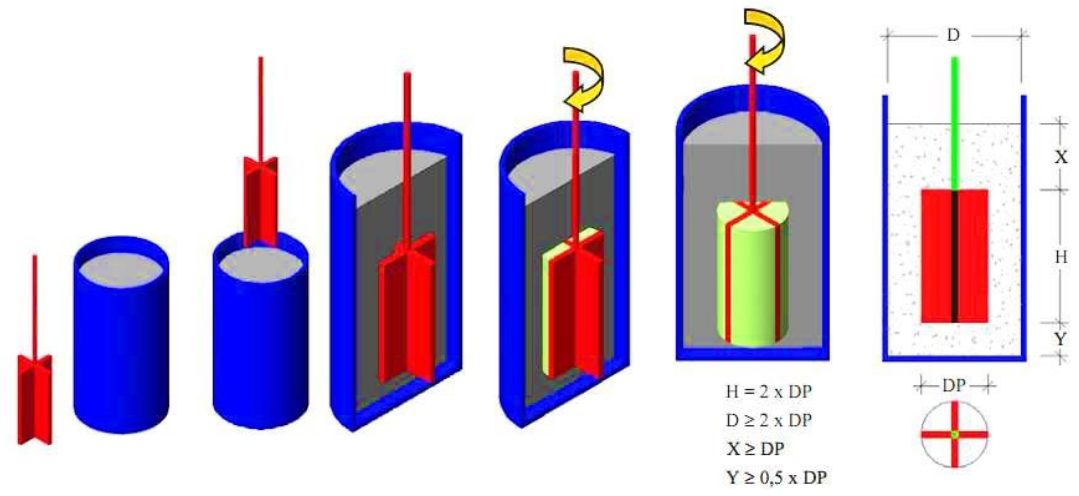

Figura 1: Representação esquemática do sistema Vane [25].

Para o caso das pastas de cimento, o ensaio reométrico é realizado, frequentemente, pelo reômetro tipo cilindros coaxiais ou placa-placa. As argamassas podem ser avaliadas por diferentes tipos de geometria, podendo ser ensaiadas com o sistema Vane, quando observadas limitações das outras geometrias frente ao sistema particulado mais elevado desse material [10]. Entretanto, no caso dos concretos, a caracterização reológica apresenta algumas dificuldades devido às grandes dimensões das partículas de agregado graúdo, impedindo o uso de reômetros tradicionais. Porém, reômetros com dimensões suficientemente grandes vêm sendo desenvolvidos, possibilitando a caracterização reológica desses materiais [11].

\subsubsection{Técnica de Pashias}

Os modelos de correlação da medida de slump com a tensão limite de escoamento tiveram seu desenvolvimento a partir da década de 1980 com MURATA [5], consolidando-se com as pesquisas de CHRISTENSEN [6] e PASHIAS et al. [4]. Com o tempo, o aperfeiçoamento desses modelos foi sendo realizado, destacandose os trabalhos de ROUSSEL [26] e PIERRE et al. [8], nos quais uma análise dos diferentes mecanismos relacionados ao slump é proposto.

Novos métodos simplificados (condição de modelo de Bingham) para obtenção dos parâmetros reoló- 
gicos têm sido desenvolvidos, como por exemplo aqueles que correlacionam a tensão limite de escoamento e viscosidade plástica a partir do mini slump test [27] ou os que medem tensão limite de escoamento a partir de um plano inclinado, os chamados testes da calha [19].

A técnica de Pashias, desenvolvida inicialmente para analisar a tensão limite de escoamento de concretos frescos [4], foi modificada com o intuito de abranger um campo maior de materiais, como argamassas, géis, soluções altamente floculadas, lodo de esgoto, etc [7, 28, 29].

$\mathrm{O}$ método consiste em medir o abatimento do material que preenche um cilindro, e que uma vez retirado, deixa o material fluir sobre uma superfície horizontal. Então, mede-se a diferença entre a altura inicial e altura final do material deformado, associando a ele uma tensão limite de escoamento.

O método de Pashias faz uso dos seguintes materiais (Figura 2): placa metálica retangular de superfície lisa, com eixo vertical posicionado em seu centro; cilindro de PVC, onde é colocada a amostra; disco metálico e massa adicional.

Para materiais cuja previsão de tensão limite de escoamento é elevada, BAUDEZ et al. [7], sugerem dispor uma massa adicional sobre a amostra a fim de bem conduzir os ensaios.



Figura 2: Aparato experimental utilizado na técnica de Pashias [30].

No ensaio, um recipiente cilíndrico de PVC aberto em ambas as extremidades e posicionado sobre uma placa metálica plana e horizontal é preenchido com a amostra em camadas, sendo posteriormente colocado um disco metálico no topo da amostra. Em seguida, o recipiente é levantado verticalmente e o material sofre um abatimento, o qual é medido.

A Figura 3 ilustra o comportamento de tensões do material durante o ensaio. A tensão limite de escoamento ou crítica $\left(\tau_{c}\right)$ é determinada indiretamente, no método de Pashias, a partir das equações apresentadas de (1) a (6).

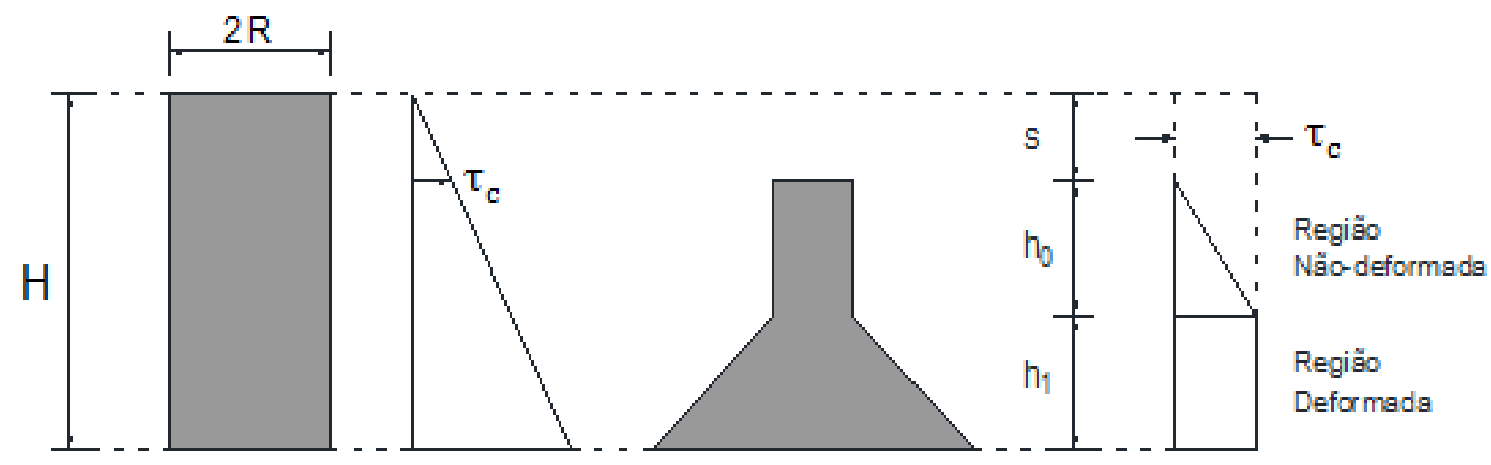

Figura 3: Distribuição de tensões antes e após o abatimento [4].

A pressão exercida pela presença da massa adicionada no topo da amostra $\left(\mathrm{P}_{\circ}\right)$, se necessária, é apresentada na Equação 1: 


$$
\mathrm{P}_{0}=\frac{\mathrm{m}_{0}}{\pi R^{2}} \mathrm{~g}
$$

onde $\mathrm{m}_{0}$ é a massa adicionada no topo da amostra, $\mathrm{R}$ é o raio do cilindro onde está contido o material e g é a aceleração da gravidade.

A pressão total (P) resultante no material é caracterizada pela Equação 2:

$$
\mathrm{P}=\rho g \mathrm{H}+\mathrm{P}_{0}
$$

A adição da massa é equivalente a um "aumento da altura" da amostra representado pela Equação 3:

$$
\mathrm{Z}_{0}=\frac{\mathrm{m}_{0}}{\rho \pi \mathrm{R}^{2}}
$$

onde $\mathrm{Z}_{0}$ é o aumento fictício de altura do material.

A partir dessas considerações, a tensão limite de escoamento $\left(\tau_{c} \tau c\right)$ é determinada pela Equação 4:

$$
\mathrm{h}_{\mathrm{o}}=\frac{2 \tau_{\mathrm{c}}}{\mathrm{pg}}-\mathrm{Z}_{\mathrm{o}}
$$

sendo $\mathrm{h}_{0}$ a altura não-deformada.

Com base na Equação 5 é determinado a altura $\left(h_{1}\right) h 1$ da região deformada, usando a altura equivalente da amostra $\left(\mathrm{H}+\mathrm{Z}_{0}\right)$.

$$
\mathrm{h}_{1}=\frac{2 \tau_{\mathrm{c}}}{\mathrm{pg}} \ln \left(\frac{\mathrm{\rho g}}{2 \tau_{\mathrm{c}}}\left(\mathrm{H}+\mathrm{Z}_{\mathrm{o}}\right)\right)
$$
quação 6:

Por meio das Equações 4 e 5 pode-se escrever o slump modificado ou abatimento (s) conforme a e-

$$
\mathrm{s}=\mathrm{H}-\left(\mathrm{h}_{\mathrm{o}}+\mathrm{h}_{1}\right)=\mathrm{H}+\mathrm{Z}_{\mathrm{o}}-\frac{2 \tau_{\mathrm{c}}}{\rho \mathrm{g}}\left(1+\ln \frac{\rho \mathrm{g}\left(\mathrm{H}+\mathrm{Z}_{\mathrm{o}}\right)}{2 \tau_{\mathrm{c}}}\right)
$$

onde $\mathrm{H}$ é a altura do cilindro preenchido pelo material e $\rho$ sua $\rho$ massa específica.

\section{MATERIAIS E MÉTODOS}

\subsection{Materiais}

O cimento utilizado nas composições das argamassas produzidas e analisadas neste artigo foi o cimento Portland composto com escória granulada de alto forno e classe de resistência de $32 \mathrm{MPa}$ aos 28 dias (CP II E 32), com massa específica de $3,05 \mathrm{~g} / \mathrm{cm}^{3}$ e superfície específica de $4,031 \mathrm{~cm}^{2} / \mathrm{g}$. Utilizaram-se dois tipos de agregado miúdo, a areia natural média, com massa específica de $2,62 \mathrm{~g} / \mathrm{cm}^{3}$, e módulo de finura e dimensão máxima de, respectivamente, 2,02 e 4,75 mm, além da areia 80-100, cuja massa específica é de $2,64 \mathrm{~g} / \mathrm{cm}^{3}$ (este material se caracteriza como uma areia industrial, voltada à produção de filtros, vidros e cerâmicas e comercializada por mineradoras). A adição mineral utilizada nas composições dos concretos foi a sílica ativa não-densificada, obtida a partir da fabricação de silício metálico ou de ligas de ferro silício (MS 920U), com massa específica de $2,40 \mathrm{~g} / \mathrm{cm}^{3}$ e superfície específica de $150.000 \mathrm{~cm}^{2} / \mathrm{g}$. O aditivo químico utilizado foi o superplastificante de terceira geração à base de éter policarboxílico (ADVA $\left.{ }^{\mathrm{TM}} 175\right)$ com massa específica de $1,08 \mathrm{~g} / \mathrm{cm}^{3}$. E, por fim, utilizou-se água proveniente da rede pública de abastecimento da cidade de Ilha Solteira/SP com massa específica de de $1,00 \mathrm{~g} / \mathrm{cm}^{3}$.

\subsection{Composições das argamassas de CAD}

As composições de argamassas utilizadas nesta pesquisa foram obtidas a partir de traços de concreto de alto desempenho (CAD) dosado por OLIVEIRA [10] segundo dois métodos distintos de dosagem.

OLIVEIRA [10] realizou um estudo de dosagens de CAD, partindo de uma composição inicial de 
concreto de alto desempenho, sendo então utilizado dois diferentes métodos de dosagem de concreto, os conceitos de reologia e de empacotamento de partículas, a fim de atingir melhorias nas propriedades reológicas e mecânicas desses concretos. Com base nos conceitos de reologia, foram determinados, por meio do estudo reológico da pasta de cimento e da argamassa, os teores ótimos de sílica ativa e de aditivo superplastificante. Por outro lado, com base nos conceitos de empacotamento de partículas, utilizados por OLIVEIRA [10], foi determinada a proporção ótima dos componentes particulados a partir do modelo de Alfred [12], com coeficiente de distribuição de 0,29 .

Quando da dosagem do concreto com base no empacotamento de partículas, verificou-se a ausência de determinados tamanhos de partículas. Em virtude disso, OLIVEIRA [10] selecionou novos materiais (pedrisco, pó de pedra e areia 80-100) para a produção de uma composição de CAD com melhor distribuição granulométrica. O CAD dosado por meio dos conceitos de empacotamento de partículas apresenta uma melhor distribuição granulométrica, função do melhor preenchimento dos vazios do concreto, quando comparado ao CAD dosado com base nos conceitos de reologia. Assim para avaliar as argamassas obtidas a partir dos concretos dosados por OLIVEIRA [10], é apresentada na Figura 4 a distribuição granulométrica dos traços produzidos, porém considerando apenas os materiais que compõem as argamassas.

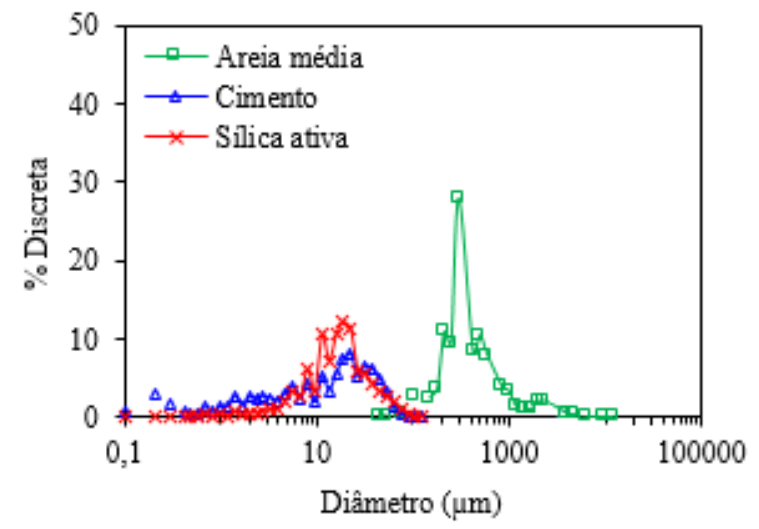

(a)

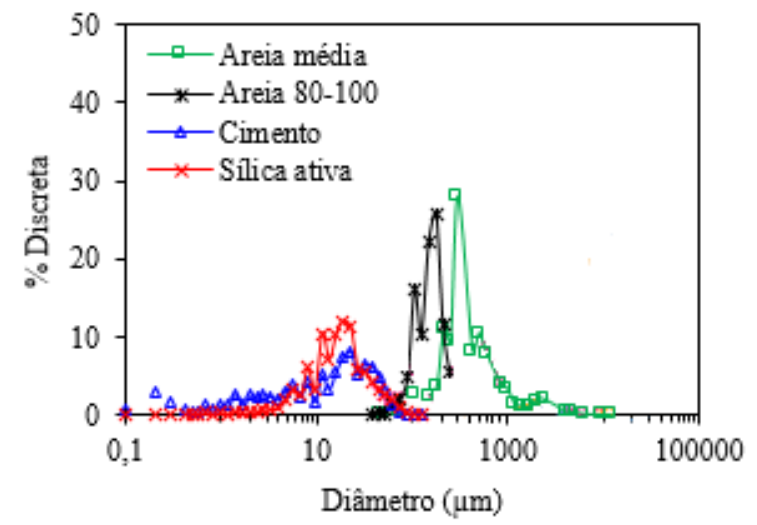

(b)

Figura 4: Distribuição granulométrica discreta dos materiais da: (a) argamassa dosada por reologia e (b) argamassa dosada por empacotamento de partículas [10].

As argamassas produzidas receberam as seguintes designações: argamassa CAD 1, obtida a partir do concreto dosado com base nos conceitos de reologia (menor empacotamento) e argamassa CAD 2, obtida a partir do concreto dosado com base nos conceitos de empacotamento de partículas (maior densidade de empacotamento).

A Tabela 1 apresenta a composição da argamassa CAD 1 (argamassa com menor densidade de empacotamento) e argamassa CAD 2 ( argamassa com maior densidade de empacotamento).

Tabela 1: Composições das argamassas CAD 1 e CAD 2.

\begin{tabular}{|c|c|c|c|c|c|c|c|}
\hline \multirow{2}{*}{$\begin{array}{c}\text { Relação } \\
\text { Água/Aglomerante }\end{array}$} & \multirow{2}{*}{$\begin{array}{c}\text { Relação } \\
\text { Água/Materiais } \\
\text { Secos (\%) }\end{array}$} & \multirow{2}{*}{$\begin{array}{c}\text { Água } \\
\left(\mathrm{kg} / \mathrm{m}^{3}\right)\end{array}$} & \multirow{2}{*}{$\begin{array}{l}\text { Cimento } \\
\left(\mathrm{kg} / \mathrm{m}^{3}\right)\end{array}$} & \multirow{2}{*}{$\begin{array}{c}\text { Sílica } \\
\text { ativa } \\
\left(\mathrm{kg} / \mathrm{m}^{3}\right)\end{array}$} & \multicolumn{2}{|c|}{ Agregado Miúdo $\left(\mathrm{kg} / \mathrm{m}^{3}\right)$} & \multirow{2}{*}{$\begin{array}{l}\text { Aditivo } \\
\left(\mathrm{kg} / \mathrm{m}^{3}\right)\end{array}$} \\
\hline & & & & & $\begin{array}{l}\text { Areia } \\
\text { Média }\end{array}$ & Areia $80-100$ & \\
\hline \multicolumn{8}{|c|}{ ARGAMASSA CAD 1} \\
\hline 0,31 & 12,50 & 254,13 & 740,79 & 82,22 & 1211,30 & - & 7,41 \\
\hline \multicolumn{8}{|c|}{ ARGAMASSA CAD 2} \\
\hline 0,34 & 15,00 & 287,38 & 638,75 & 212,98 & 638,75 & 425,78 & 10,23 \\
\hline
\end{tabular}

\subsection{Produção da argamassa}

$\mathrm{O}$ procedimento de mistura adotado foi o mesmo para ambas as argamassas produzidas, obedecendo à sequência pré-definida por OLIVEIRA [10]: 
- Primeiramente, o agregado miúdo e metade da água foram misturados, na velocidade baixa, por trinta segundos em uma argamassadeira, sendo em seguida misturados na velocidade rápida por mais trinta segundos;

- Em seguida, adicionou-se o cimento e a sílica ativa, e o restante da água. Misturou-se por trinta segundos na velocidade baixa e mais dois minutos e meio na velocidade rápida;

- Então, o processo de mistura foi interrompido por três minutos para repouso da argamassa e limpeza das pás e da cuba da argamassadeira;

- Por fim, o processo de mistura foi reiniciado por mais um minuto na velocidade baixa e, logo depois, adicionou-se o superplastificante, batendo a mistura por mais cinco minutos na velocidade rápida.

\subsection{Determinação da tensão limite de escoamento}

Realizado o processo de mistura, foram determinadas as tensões limite de escoamento das argamassas CAD 1 e CAD 2 em dois diferentes tempos, 5 e 60 minutos após a incorporação do aditivo superplastificante à mistura. Assim, no tempo de 5 minutos, as argamassas foram ensaiadas, simultaneamente, pelo ensaio reométrico e pela técnica de Pashias. Este segundo método forneceu os abatimentos das argamassas, e por meio da equação 6, foram inferidas as tensões limites de escoamento. Passados 60 minutos, este procedimento de ensaio foi novamente realizado.

Para o ensaio reométrico, foi utilizado o reômetro Brookfield R/S, e em função da composição da argamassa, com sistema particulado maior, empregou-se o sistema Vane 40/20, conforme ilustrado na Figura 5. O procedimento consistiu em impor ao material uma taxa de tensão cisalhante a fim de obter a sua deformação. Inicialmente o material foi cisalhado por $15 \mathrm{~s}$ com o objetivo de homogeneizar o sistema particulado, ficando em repouso por mais $15 \mathrm{~s}$, sendo, após isso, cisalhado por $60 \mathrm{~s}$ até atingir $700 \mathrm{~Pa}$ conforme ilustrado na Figura 7.a.

Para a análise do ensaio reométrico utilizou-se o software Rheocad 2000, o qual dispõe de vários modelos reológicos (modelo de Newton, Bingham, Herschel-Bulkley dentre outros). Na obtenção dos resultados de tensão limite de escoamento definiu-se, a partir do Rheocad 2000, o modelo reológico de melhor ajuste aos dados e delimitou-se a deformação do material em $150 \mathrm{~s}^{-1}$. Com intuito de manter um padrão de ensaio, os procedimentos experimentais foram realizados em sala climatizada com temperatura de $(24 \pm 1)^{\circ} \mathrm{C}$.
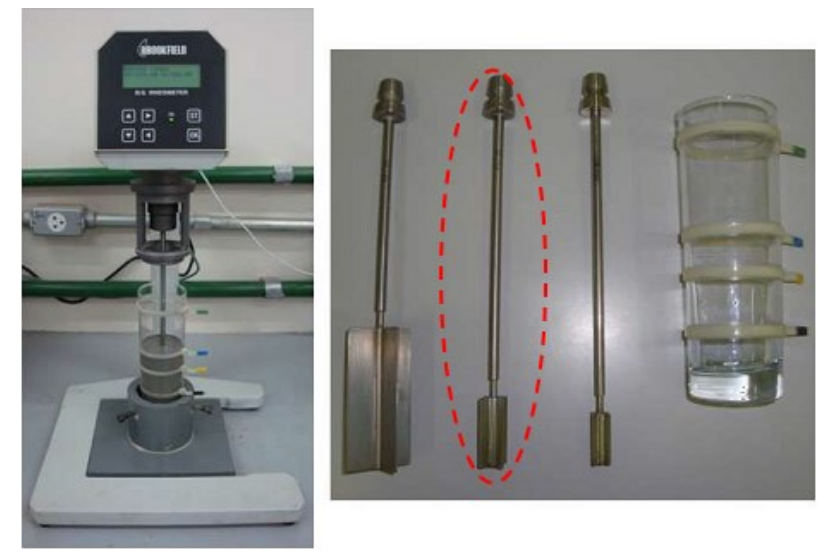

Figura 5: Reômetro R/S e as palhetas do sistema Vane (a palheta destacada corresponde à utilizada no ensaio da argamassa - palheta 40/20) [10].

Simultaneamente, por meio do cilindro de Pashias, obtiveram-se os abatimentos das argamassas. Para a realização da técnica de Pashias, utilizou-se: uma placa de aço inoxidável com um eixo vertical disposto no seu centro, um cilindro de PVC de $300 \mathrm{~mm}$ de altura e diâmetro interno de $145,8 \mathrm{~mm}$ e um disco metálico de $145 \mathrm{~g}$ sobre a amostra, sem massas adicionais $\left(m_{0}=145 \mathrm{~g}\right)$, conforme ilustrado na Figura 6 . 


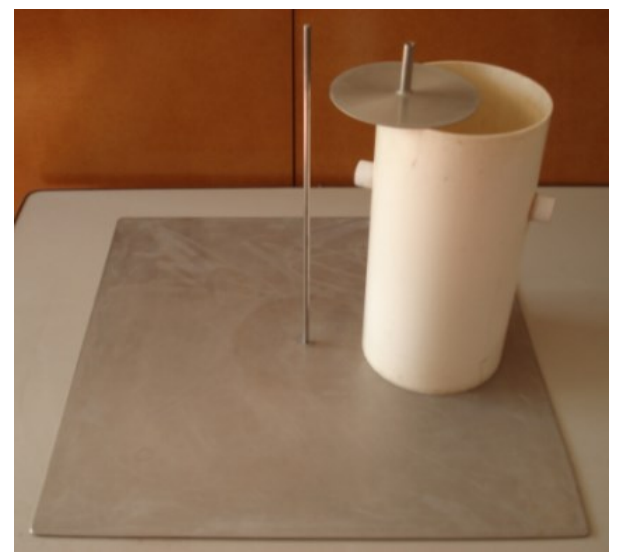

Figura 6: Aparato utilizado na técnica de Pashias.

\section{RESULTADOS E DISCUSSÕES}

\subsection{Tensões limites de escoamento das argamassas: técnica de Pashias e reometria rotacional}

Os resultados experimentais obtidos na pesquisa envolvem todos os parâmetros necessários para o cálculo da tensão limite de escoamento, a saber: massa específica das argamassas, valores de abatimento para as composições estabelecidas e as dimensões do molde cilíndrico. Determinaram-se dois valores para as tensões limite de escoamento, obtidos por meio da:

- Técnica de Pashias, utilizando a equação 6;

- Reometria rotacional, utilizando o sistema Vane e o software Rheocad 2000, tendo como melhor ajuste reológico o modelo de Herschel-Bulkley $\left(\tau=\tau_{c}+\mathrm{k}_{n} \cdot \dot{\gamma}^{n}\right)$ a três parâmetros $\left(\tau_{c}\right.$, $\mathrm{k}_{n}$ e $n$ ), onde $\tau$ é a tensão de cisalhamento; $\dot{\gamma}$ a taxa de deformação; $\tau_{c}$ tensão limite de escoamento; $\mathrm{k}_{n} \mathrm{o}$ índice de consistência e $n$ o índice de escoamento.

A Figura 7.b mostra o resultado experimental do comportamento reológico da argamassa CAD 2 nos tempos de 5 e 60 minutos, ilustrando seu bom ajuste ao modelo de Herschel-Bulkley.

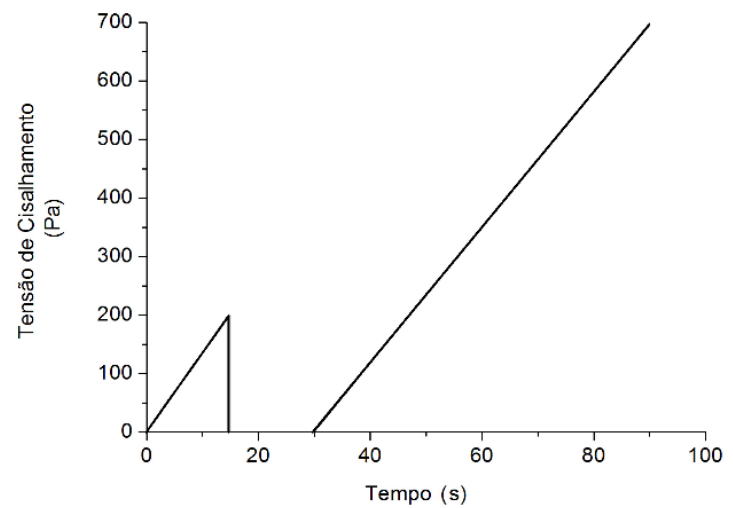

(a)

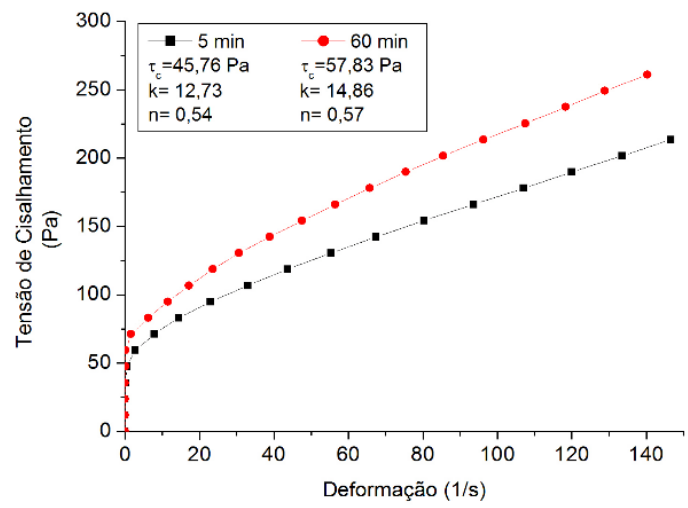

(b)

Figura 7: Curvas de interesse: (a) programa de cisalhamento imposto na análise reológica da argamassa e (b) curvas de tensão de cisalhamento versus deformação em dois instantes distintos.

A Tabela 2 apresenta os valores de tensão limite de escoamento obtidos pela técnica de Pashias e pelo reômetro, bem como os percentuais de erro entre as medidas. Tais dados experimentais permitiram a comparação dos métodos de análise reológica utilizados e a avaliação da técnica de Pashias como método alternativo para obtenção do parâmetro tensão limite de escoamento. 
Tabela 2: Tensões limite de escoamento e erros percentuais das argamassas CAD 1 e CAD 2.

\begin{tabular}{|c|c|c|c|c|c|c|}
\hline \multirow{2}{*}{ Ensaios } & \multirow{2}{*}{$\begin{array}{c}\text { Tempo } \\
\text { (min) }\end{array}$} & \multirow{2}{*}{$\underset{\left(\mathbf{k g} / \mathrm{m}^{3}\right)}{\rho}$} & \multirow{2}{*}{$\begin{array}{c}\mathrm{s} \\
(\mathrm{cm})\end{array}$} & \multicolumn{2}{|c|}{ Tensão Limite de Escoamento (Pa) } & \multirow{2}{*}{ Erro (\%) } \\
\hline & & & & PASHIAS & REÔMETRO & \\
\hline \multicolumn{7}{|c|}{ ARGAMASSA CAD 1} \\
\hline 1 & \multirow{5}{*}{5} & 2216,14 & 28,00 & 50,11 & 44,54 & 12,51 \\
\hline 2 & & 2236,10 & 27,70 & 58,47 & 53,26 & 9,78 \\
\hline 3 & & 2256,07 & 27,80 & 56,18 & 52,80 & 6,40 \\
\hline 4 & & 2216,14 & 27,80 & 55,36 & 56,14 & 1,39 \\
\hline 5 & & 2196,18 & 27,80 & 54,96 & 54,55 & 0,75 \\
\hline 1 & \multirow{5}{*}{60} & 2276,03 & 27,60 & 61,20 & 63,45 & 3,55 \\
\hline 2 & & 2196,17 & 27,50 & 63,00 & 61,35 & 2,69 \\
\hline 3 & & 2236,10 & 27,50 & 63,95 & 65,79 & 2,80 \\
\hline 4 & & 2196,18 & 27,40 & 65,65 & 78,42 & 16,28 \\
\hline 5 & & 2176,21 & 27,30 & 67,99 & 76,98 & 11,68 \\
\hline
\end{tabular}

ARGAMASSA CAD 2

\begin{tabular}{|c|c|c|c|c|c|c|}
\hline 1 & \multirow{5}{*}{5} & 2176,21 & 28,30 & 41,88 & 43,77 & 4,32 \\
\hline 2 & & 2156,24 & 28,20 & 44,03 & 46,22 & 4,74 \\
\hline 3 & & 2156,24 & 28,50 & 36,79 & 45,1 & 18,43 \\
\hline 4 & & 2236,11 & 28,50 & 37,80 & 44,74 & 15,51 \\
\hline 5 & & 2176,21 & 28,50 & 37,04 & 45,76 & 19,06 \\
\hline 1 & \multirow{5}{*}{60} & 2196,17 & 27,90 & 52,34 & 56,28 & 7,00 \\
\hline 2 & & 2176,21 & 28,10 & 46,85 & 49,92 & 6,15 \\
\hline 3 & & 2176,21 & 28,00 & 49,39 & 53,37 & 7,46 \\
\hline 4 & & 2176,21 & 28,10 & 46,85 & 52,46 & 10,69 \\
\hline 5 & & 2156,25 & 28,00 & 49,02 & 57,83 & 15,23 \\
\hline
\end{tabular}

A partir da Tabela 2, observa-se que as argamassas analisadas, tanto no tempo de 5 minutos como no tempo de 60 minutos, apresentaram valores aproximados de tensão limite de escoamento em ambos os métodos de análise (com erros inferiores a 20\%, considerando a reometria clássica como referência). Esse comportamento de proximidade da tensão limite de escoamento foi constatado em ambas as argamassas analisadas.

O bom comportamento da técnica de Pashias (técnica alternativa de caracterização reológica) frente ao método de reometria rotacional é, a partir da comparação dos valores de tensão limite de escoamento apresentados na Tabela 2, verificado e atestado. Essa constatação vai ao encontro dos primeiros trabalhos referentes à técnica de Pashias, como o BAUDEZ et al. [7], e também, mais recentemente, aos de LEMOS et al. [30], SIVA NETO et al. [31] e BARBOSA [28], corroborando a capacidade da técnica de Pashias em fornecer o parâmetro tensão limite de escoamento. Resultados satisfatórios, quando do uso da técnica de Pashias, também têm sido citados na literatura, na determinação de tensões limite de escoamento para materiais da indústria mineradora $[32,33]$.

A média das tensões limite de escoamento, assim como o desvio padrão e coeficiente de variação dos dados obtidos, para os dois casos analisados, são apresentados na Tabela 3.

Tabela 3: Tratamento estatístico dos resultados de tensões limite de escoamento das argamassas CAD 1 e CAD 2.

\section{PARÂMETROS}

PASHIAS

REÔMETRO 


\begin{tabular}{l|c|c|c|c}
\hline & $T=5 \mathrm{~min}$ & $\mathrm{~T}=60 \mathrm{~min}$ & $\mathrm{~T}=5 \mathrm{~min}$ & $\mathrm{~T}=60 \mathrm{~min}$ \\
\hline
\end{tabular}

\section{ARGAMASSA CAD 1}

\begin{tabular}{c|c|c|c|c}
\hline Tensão limite de escoamento média $(\mathrm{Pa})$ & 55,02 & 64,36 & 52,26 & 69,20 \\
\hline Desvio padrão $(\mathrm{Pa})$ & 3,06 & 2,59 & 4,51 & 7,93 \\
\hline Coeficiente de variação $(\%)$ & 5,56 & 4,03 & 8,62 & 11,47 \\
\hline
\end{tabular}

\section{ARGAMASSA CAD 2}

\begin{tabular}{c|c|c|c|c}
\hline Tensão limite de escoamento média $(\mathrm{Pa})$ & 39,51 & 48,89 & 45,12 & 53,97 \\
\hline Desvio padrão $(\mathrm{Pa})$ & 3,26 & 2,26 & 0,95 & 3,13 \\
\hline Coeficiente de variação $(\%)$ & 8,25 & 4,63 & 2,10 & 5,81 \\
\hline
\end{tabular}

Além da técnica de Pashias ter possibilitado a obtenção de valores de tensão limite de escoamento próximos aos medidos pelo reômetro, os dados estatísticos apresentados na Tabela 3 demonstram que os valores de tensão limite de escoamento obtidos por tal técnica apresentaram baixos desvio padrão e coeficiente de variação, corroborando para a capacidade desse método alternativo.

Outra constatação realizada a partir da Tabela 3 diz respeito ao comportamento dos dados obtidos pelo reômetro com passar do tempo. Nota-se que os valores de tensão limite de escoamento obtidos a partir do reômetro apresentaram maiores desvios padrão no tempo de 60 minutos, em ambas as argamassas, demonstrando a dificuldade do reômetro utilizado em analisar argamassas com fenômenos de aglomeração e hidratação mais avançado, isto, provavelmente, devido a uma limitação de torque do equipamento, problema também constatado por ESTELLÉ et al. [34] em sua pesquisa. Comportamento oposto é observado quando da análise dos resultados de tensão de limite de escoamento pelo reômetro aos $5 \mathrm{~min}$, nota-se, para as duas argamassas, pequenos desvio padrão nesse tempo de referência.

A comparação dos valores de tensão limite de escoamento com o passar do tempo é apresentado na Figura 8. Observa-se que com o passar do tempo, de 5 para 60 minutos, devido ao endurecimento da argamassa causado pelas reações químicas de seus componentes, houve o aumento da tensão limite de escoamento.

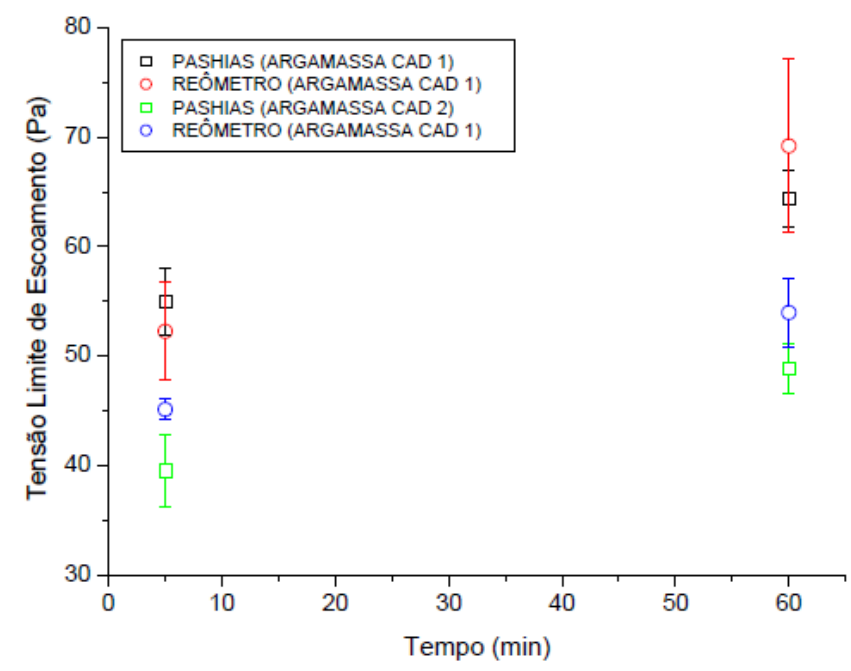

Figura 8: Comparativo entre as tensões limite de escoamento obtidas para as duas argamassas analisadas.

Visualmente, o aumento da tensão limite de escoamento é observado a partir da Figura 9 e Figura 10. Em ambas as imagens nota-se a diminuição do espalhamento da argamassa no decorrer do tempo, de 5 min para 60 min, indicando o aumento de sua consistência em virtude do processo crescente de hidratação [35]. 


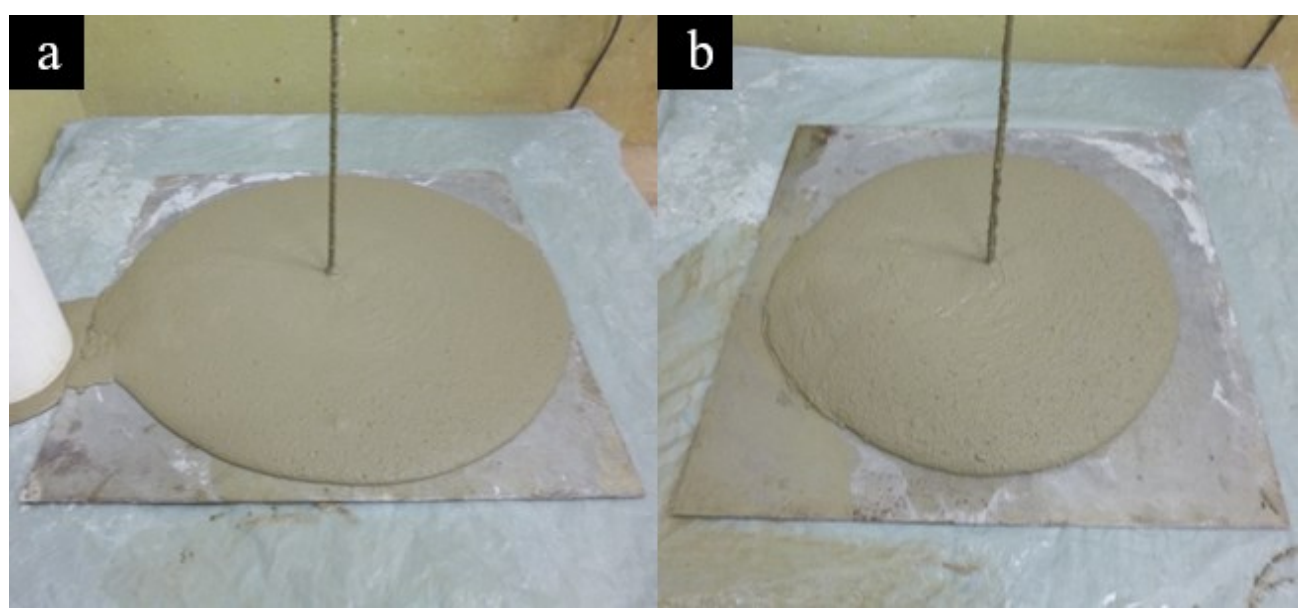

Figura 9: Argamassa CAD 1: (a) 5 min após a incorporação do superplastificante e (b) 60 min após a incorporação do superplastificante.

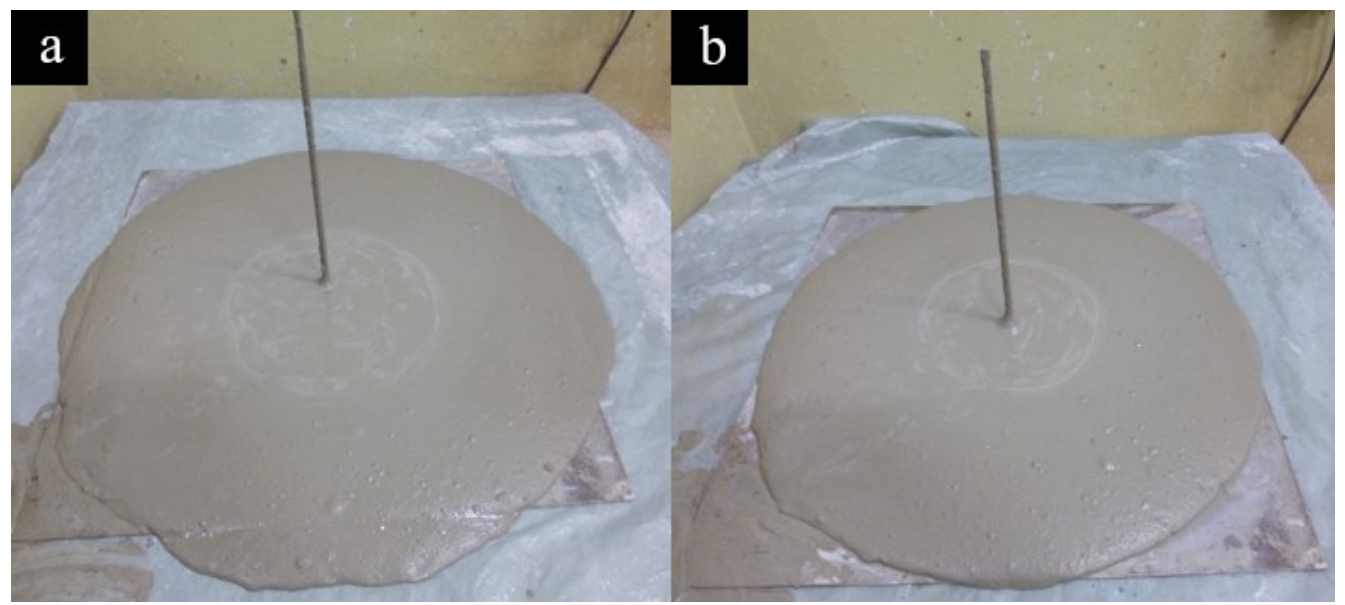

Figura 10: Argamassa CAD 2: (a) 5 min após a incorporação do superplastificante e (b) 60 min após a incorporação do superplastificante.

Quando comparadas as imagens (Figura 9 e Figura 10) observa-se que há uma diferença de espalhamento entre elas, a argamassa CAD 1 apresentou menor espalhamento em relação à argamassa CAD 2, ou seja, a primeira apresentou-se menos fluida que a segunda. Este comportamento é confirmado a partir dos valores de tensão limite de escoamento, à medida que aumentou-se esse parâmetro reológico, verificou-se acréscimos da viscosidade aparente das argamassas (conforme Figura 7.b, Figura 9 e Figura 10), e portanto, diminuição de sua fluidez e menor espalhamento. Em relação à influência da mudança do material da placa observada na Figura 10, BAUDEZ et al. [7] afirma que a superfície inferior não produz influências significativas sobre o resultado do escoamento do material.

Considerando os resultados da argamassa CAD 2, é possível afirmar, a partir da Tabela 2, que seus valores de tensão limite de escoamento foram menores que os medidos na argamassa CAD 1. Esse comportamento deve-se à argamassa CAD 2, de maior densidade de empacotamento, ter em sua composição maiores quantidades de superplastificante e sílica.

A queda do valor de tensão limite de escoamento para composições cimentícias com maior quantidade de sílica ativa já foi comprovada em outros trabalhos. De acordo com REIS [9], as pequenas partículas de sílica agem como esferas rolantes no concreto, passando a compor a solução de água do poro, promovendo, consequentemente, o aumento de fluidez da mistura. Trabalhos mais recentes, como os de LU et al. [18] e BENAÍCHA et al. [36] comprovam a influência da sílica ativa no comportamento reológico das argamassas. Segundo LU et al. [18], o aumento significativo da sílica ativa promove a diminuição da tensão limite de escoamento e, consequentemente, a queda da viscosidade, acarretando, portanto, maior fluidez à argamassa. Outro aspecto observado na argamassa CAD 2, além da sua elevada fluidez, foi a sua consistência, ela se apresentou "pegajosa" quando comparada com a argamassa CAD 1. Essa "aparência pegajosa" está ligada ao 
aumento da quantidade de sílica ativa à mistura, fato este já constatado no trabalho de ZAIN et al. [37].

Uma outra constatação relacionada à influência da sílica ativa é observada a partir da Figura 8, através da qual verifica-se que as argamassas com maior quantidade de sílica ativa (argamassa CAD 2) apresentaram menores variações da tensão limite de escoamento, quer seja em 5 ou 60 minutos, em ambos os métodos de ensaio. Esse comportamento também foi constatado por AÏTCIN [38], o qual afirma que a sílica ativa facilita o controle do comportamento reológico do concreto fresco.

Outro fator contribuinte para a diminuição da tensão limite de escoamento da argamassa CAD 2, o superplastificante, também apresenta papel importante nas propriedades reológicas dos materiais cimentícios. Segundo GARCÍA-TAENGUA et al. [39],variações na dosagem do superplastificante afetam a tensão limite de escoamento das argamassas, sendo que argamassas com maior quantidade de superplastificante, caso da argamassa $\mathrm{CAD} 2$ em relação à argamassa $\mathrm{CAD} 1$, apresentam menor tensão limite de escoamento e redução da viscosidade, e consequentemente, aumento da fluidez.

\section{CONCLUSÕES}

A técnica de Pashias mostrou-se adequada para se avaliar argamassas dosadas por diferentes métodos, demonstrando que indiferentemente do método de dosagem, reologia ou empacotamento de partículas, essa técnica expedita é capaz de avaliar, satisfatoriamente, o parâmetro tensão limite de escoamento. Ademais, a partir do estudo realizado, pôde-se verificar que a técnica de Pashias, geralmente utilizada para a análise de materiais com elevada tensão limite de escoamento resultou, quando da análise de material com maior fluidez (argamassa CAD 2), em valores de tensão limite de escoamento de mesma ordem de grandeza daqueles medidos pela reometria clássica. Essa constatação demonstra a boa capacidade da técnica de Pashias, técnica alternativa, em caracterizar o comportamento reológico dos materiais, não só daqueles com elevada tensão limite de escoamento, mas também dos que apresentam baixa tensão limite de escoamento.

\section{BIBLIOGRAFIA}

[1] STARON, L., LAGREÉE, P. Y., RAY, P., POPINET, S., "Scaling laws for the slumping of a Bingham plastic fluid", Journal of Rheology, v. 57, n. 4, pp. 1265-1280, 2013.

[2] ROUSSEL, N., "Correlation between yield stress and slump: comparison between numerical simulations and concrete rheometers results", Materials and Structures, v. 39, n. 4, pp. 501-509, 2006.

[3] GARCIA-BERNET, D., LOISEL, D., GUIZAR, G., BUFFIÈRE, P., STEYER, J. P., ESCUDIÉ, R., "Rapid measurement of the yield stress of anaerobically-digested solid waste using slump tests", Waste management, v. 31, n. 4, pp. 631-635, 2011.

[4] PASHIAS, N., BOGER, D.V., SUMMERS, J., GLENISTER, D.J., "A fifty cent rheometer for yield stress measurement", Journal of Rheology, v. 40, n. 6, pp. 1179-1189, Nov.-Dez. 1996.

[5] MURATA, J., "Flow and deformation of fresh concrete", Materials an Structures, v.17, n.98, pp. 117129, Mar.-Apr. 1984

[6] CHRISTENSEN, G., Modelling the flow of fresh concrete: the slump test, Tese de D.Sc., Princeton University, Princeton, New Jersey, USA, 1991.

[7] BAUDEZ, J. C., CHABOT F., COUSSOT P., "Rheological interpretation of the slump test", Applied Rheology, v. 12, n. 3, pp. 133-141, 2002.

[8] PIERRE, A., LANOS, C., ESTELLÉ, P., "Extension of spread-slump formulae for yield stress evaluation", Applied Rheology, v. 23, n. 6, pp. 63849, 2013.

[9] REIS, J. F. A., Determinação de parâmetros reológicos de concretos através do ensaio de abatimento de tronco de cone modificado: estudo de caso, Dissertação de M.Sc., Faculdade de Engenharia, Universidade Estadual Paulista, Ilha Solteira, SP, Brasil, 2008.

[10] OLIVEIRA, C. O., Análise das propriedades reológicas de materiais cimentícios associando o conceito de empacotamento de partículas, Dissertação de M.Sc., Faculdade de Engenharia, Universidade Estadual Paulista, Ilha Solteira, SP, Brasil, 2013.

[11] CASTRO, A.L., PANDOLFELLI, V. C., "Revisão: conceitos de dispersão e empacotamento de partículas para a produção de concretos especiais aplicados na construção civil", Cerâmica, v. 55, n. 333, pp. 18-32, 2009. 
[12] DINGER, D. R., FUNK, J. E., "Particle packing Part I - Fundamentals of particle packing monodisperse spheres", Interceram, v. 41, n. 1, pp. 10-14, 1992.

[13] FERRARIS, C. F., "Measurement of rheological properties of high performance concrete: state of the art report", Journal of Research of the National Institute of Standards and Technology, v. 104, n. 5, pp. 461-478, Sept.-Oct. 1999.

[14] BANFILL, P. F. G., "Rheology of fresh cement and concrete”, Rheology reviews, pp. 61-130, 2006.

[15] CARDOSO, F. A., JOHN, V. M., PILEGGI, R. G., BANFILL, P. F. G., "Characterisation of rendering mortars by squeeze-flow and rotational rheometry", Cement and Concrete Research, v.57, pp. 79-87, 2014.

[16] PUERTAS, F., VARGA, C., ALONSO, M. M., "Rheology of alkali-activated slag pastes. Effect of the nature and concentration of the activating solution", Cement and Concrete Composites, v. 53, pp. 279-288, 2014.

[17] CLAYTON, S., GRICE, T. G., BOGER, D. V., “Analysis of the slump test for on-site yield stress measurement of mineral suspensions", International journal of mineral processing, v. 70, n. 1, pp. 3-21, 2003.

[18] LU, C., YANG, H., MEI, G., "Relationship between slump flow and rheological properties of selfcompacting concrete with silica fume and its permeability", Construction and Building Materials, v. 75, pp. 157-162, 2015.

[19] GAO, J., FOURIE, A., "Using the flume test for yield stress measurement of thickened tailings", Minerals Engineering, v. 81, pp. 116-127, 2015.

[20] FOURIE, A.B., GAWU, S.K.Y., "The validity of laboratory flume data for predicting beach slopes of thickened tailings deposits", In: Proceedings 13th International Seminar on Paste and Thickened Tailings, pp. 241-254, Toronto, 2010.

[21] HENRIQUEZ, J., SIMMS, P., "Dynamic imaging and modelling of multilayer deposition of gold paste tailings”, Minerals Engineering, v. 22, pp. 128-139, 2009.

[22] BAUER, E., Revestimentos de argamassas: características e peculiaridades, Brasília, ABCP, 2006.

[23] SCHRAMM, G., Reologia e reometria: Fundamentos Teóricos e Práticos, São Paulo, Artliber, 2006.

[24] VITA, M. O., Estudo da retração plástica e da fissuração do concreto auto-adensável nas primeiras idades: avaliação da influência dos tipos de adições minerais, Dissertação de M.Sc., Faculdade de Engenharia, Universidade Estadual Paulista, Ilha Solteira, SP, Brasil, 2011.

[25] HOPPE FILHO, J., CARDOSO, F.A., CINCOTTO, M.A., et al., "Técnicas de caracterização reológica de argamassas", Revista de Ciência e Tecnologia de Materiais de Construção Civil, v. 3, n. 2, pp. 103-120, 2006.

[26] ROUSSEL, N., COUSSOT, P., "Fifty-cent rheometer for yield stress measurements: From slump to spreading flow", Journal of Rheology, v. 49, n. 3, pp. 705-718, 2005.

[27] CHOI, M., S., LEE, J. S., RYU, K.S., et al., "Estimation of rheological properties of UHPC using mini slump test" Construction and Building Materials, v. 106, pp. 632-639, 2016.

[28] BARBOSA, M. P., MACIEL, G. F., CASTRO, A. L., et al., "Determination of rheological parameters of mortar and concrete by alternative techniques", Revista IBRACON de Estruturas e Materiais, v. 4, n. 3, pp. 440-480, 2011.

[29] BAUDEZ, J. C., AYOL, A., COUSSOT, P., "Practical determination of the rheological behavior of pasty biosolids", Journal of environmental management, v. 72, n. 3, pp. 181-188. 2004.

[30] LEMOS, K. A. A. et al., "Avaliação da tensão crítica de argamassas elaboradas com aditivos superplastificante, usando a técnica de Pashias”, In: 51 Congresso Brasileiro do Concreto, v. 51, pp. 1-16, São Paulo, 2009.

[31] SILVA NETO, C. P. et al., "Determinação e avaliação da tensão de escoamento de argamassas por meio da técnica da Pashias", In: 55 Congresso Brasileiro do Concreto, v. 1, pp. 45-60, São Paulo, 2013.

[32] OSORIO, C.A H., ARAUJO, A.C., VALADÃO, G.E.S., "Estudo de características de algumas pastas minerais", Tecnologia em Metalurgia e Materiais, v. 4, n. 3, pp. 50-55, Jan.-Mar. 2008.

[33] BOGER, D. V., "Rheology of slurries and environmental impacts in the mining industry", Annual review of chemical and biomolecular engineering, v. 4, pp. 239-257, 2013.

[34] ESTELLÉ, P., LANOS, C., "High torque vane rheometer for concrete: principle and validation from rheological measurements", Applied Rheology, v. 22, pp. 12881, 2012. 
[35] RASSINEUX, F., PETIT, J. C., MEUNIER, A., "Ancient Analogues of Modern Cement: Calcium Hydrosilicates in Mortars and Concretes from Gallo-Roman Thermal Baths of Western France", Journal of the American Ceramic Society, v. 72, n. 6, pp. 1026-1032, 1989.

[36] BENAICHA, M., ROGUIEZ, X., JALBAUD, O., et al., "Influence of silica fume and viscosity modifying agent on the mechanical and rheological behavior of self-compacting concrete", Construction and Building Materials, v. 84, pp. 103-110, 2015.

[37] ZAIN, M. F. M., SAFIUDDIN, M., YUSOF, K.M., "A study on the properties of freshly mixed high performance concrete", Cement and Concrete Research, v. 29, n. 9, pp. 1427-1432, Sept. 1999.

[38] AÏTCIN, P. C., Concreto de alto desempenho, São Paulo, PINI, 2000.

[39] GARCÍA-TAENGUA, E., SONEBI, M., HOSSAIN, K. M. A., et al., "Effects of the addition of nanosilica on the rheology, hydration and development of the compressive strength of cement mortars", Composites Part B: Engineering, v. 81, pp. 120-129, 2015. 